As the scientific community has made abundantly clear to ULM, natural-history museum collections - which are under threat across the United States and worldwide - are not just dusty old animals and plants in drawers and jars. They are resources that help us to understand our planet. And ULM's collections are proudly local: the herbarium is believed to hold samples of more than $99 \%$ of the plants found in the state. So they could help scientists to find out how the local flora has changed, and how it might be affected by future pressures.

In recent years, Nature has published much on the importance of such collections. New species are routinely discovered by curators as they examine collected creatures. In some cases, these species are no longer with us - all that remains are their remains.

At the same time, digitization is opening up collections to an everwidening pool of researchers. Many collections can now be seen online, and more are moving there. On 3 April, the Royal Botanic Gardens, Kew, in London launched Plants of the World Online - a project that it hopes will include information on all the world's known seed-bearing plants by 2020 . World Flora Online, a related project run by an international consortium, aims eventually to create a full inventory of all plant life.

Adding computed-tomography scans, isotope data and genetic data will turn online collections into hugely powerful tools for researchers. But this does not mean that the physical specimens can be discarded. New technologies will emerge that researchers will be able to apply to the things preserved by long-gone scientists.

And although the Internet is often accused of driving the decline in use of some bricks-and-mortar establishments, it could benefit museum collections. Now that scientists can rapidly identify which items are kept where, and what data are available on them, access can become easier

and more productive. Digitization enhances the value of the specimens, but it does not dispense with the need to have them: for some work, having the physical items is essential.

Of course, universities are financially constrained, and boxes of dead things in a disused basement might not seem worth saving. ULM

"In some cases, these species are no longer with us - all that remains are their remains." says that its collections were not being used much. But that's likely to be because they were neglected by those allocating resources, not because they weren't useful. To be useful, such collections must be used.

There is hope. Last year, 120,000 specimens from the Tulane University Herbarium in New Orleans, Louisiana, were moved to Louisiana State University in Baton Rouge, to become part of its collections. Other collections have also moved there in recent years.

Uniting collections in regional hubs could be a good option. It will make them cheaper to maintain, and will turn them into one-stop-shops for biologists, preserving the link to local ecosystems and enabling them to continue serving the region in which the specimens were collected. If nurtured, such growing collections will attract visiting scholars and funding. Institutions that give up their hard-won jars of fish and files of plants will one day look enviously at what they have discarded.

If ULM cannot see the value in its collections, others can. And if the university wants to be taken seriously as a place of learning, it should make a gesture towards those outraged by the handling of these plants and fish. The least it could do is offer to pay the cost of moving the collections to their new, more welcoming homes. Dare we nerds suggest to the jocks a fundraising track meet at the stadium? Go Warhawks!

\section{Still growing}

On the centenary of its publication, On Growth and Form continues to make waves in research.

T his year marks the centenary of what seems now to be an extraordinary event in publishing: the time when a UK local newspaper reviewed a dense, nearly 800 -page treatise on mathematical biology that sought to place physical constraints on the processes of Darwinism.

And what's more, the Dundee Advertiser loved the book and recommended it to readers. When the author, it noted, wrote of maths, "he never fails to translate his mathematics into English; and he is one of the relatively few men of science who can write in flawless English and who never grudge the effort to make every sentence balanced and good."

The Dundee Advertiser is still going, although it has changed identity: a decade after the review was published, it merged with The Courier, and that is how most people refer to it today. The book is still going, too. If anything, its title - alongside its balanced and good sentences - has become more iconic and recognized as the years have ticked by.

The book is On Growth and Form by D'Arcy Thompson. This week, Nature offers its own appreciation, with a series of articles in print and online that celebrate the book's impact, ideas and lasting legacy.

Still in print, On Growth and Form was more than a decade in the planning. Thompson would regularly tell colleagues and students - he taught at what is now the University of Dundee, hence the local media interest - about his big idea before he wrote it all down. In part, he was reacting against one of the biggest ideas in scientific history. Thompson used his book to argue that Charles Darwin's natural selection was not the only major influence on the origin and development of species and their unique forms: "In general no organic forms exist save such as are in conformity with physical and mathematical laws."

Biological response to physical forces remains a live topic for research. In a paper on page 212, for example, researchers report how physical stresses generated at defects in the structures of epithelial cell layers cause excess cells to be extruded.

In a separate online publication (K. Kawaguchi et al. Nature http:// dx.doi.org/10.1038/nature22321; 2017), other scientists show that topological defects have a role in cell dynamics, as a result of the balance of forces. In high-density cultures of neural progenitor cells, the direction in which cells travel around defects affects whether cells become more densely packed (leading to pile-ups) or spread out (leading to a cellular fast-lane where travel speeds up).

A Technology Feature (page 255) investigates in depth the innovative methods developed to detect and measure forces generated by cells and proteins. Such techniques help researchers to understand how force is translated into biological function.

Thompson's influence also flourishes in other active areas of interdisciplinary research. A paper on page 173 offers a mathematical explanation for the colour changes that appear in the scales of ocellated lizards (Timon lepidus) during development (also featured on this week's cover). It suggests that the patterns are generated by a system called a hexagonal cellular automaton, and that such a discrete system can emerge from the continuous reaction-diffusion framework developed by mathematician Alan Turing to explain the distinctive patterning on animals, such as spots and stripes. (Some of the research findings are explored in detail in the News and Views section, starting on page 164.) To complete the link to Thompson, Turing cited On Growth and Form in his original work on reaction-diffusion theory in living systems.

Finally, we have also prepared an online collection of research and comment from Nature and the Nature research journals in support of the centenary, some of which we have made freely available to view for one month. The collection can be found at go.nature.com/2omjipc.

Nature is far from the only organization to recognize the centenary of Thompson's book. A full programme of events will run this year around the world, and at the D'Arcy Thompson Zoology Museum in Dundee, skulls and other specimens are being scanned to create digital 3D models. Late last month, this work was featured in The Courier. One hundred years on, Thompson's story has some way to run yet. 